\title{
FORMAÇÃO EM EJA E DIVERSIDADE(S): A EXPERIÊNCIA DE EDUCAÇÃO POPULAR DO CIVEJA / UNILAB
}

\author{
Elisangela André da Silva Costa
}

elisangelaandre@unilab.edu.br

Jacqueline Cunha da Serra Freire

jacqueline@unilab.edu.br

Ana Paula Sthel Caiado

apcaiado@unilab.edu.br

Sinara Mota Neves de Almeida

sinaramota@unilab.edu.br

Universidade da Integração Internacional da Lusofonia Afro-Brasileira

RESUMO: O presente estudo tem como objetivo refletir sobre os limites e possibilidades encontrados no desenvolvimento do Circuito Intercultural de Vivências em Educação de Jovens e Adultos (CIVEJA) - projeto vinculado ao Centro de Referência em Educação de Jovens e Adultos e Cooperação Sul-Sul (ECOSS), da Universidade da Integração Internacional da Lusofonia Afro-Brasileira (UNILAB). Metodologicamente optou-se pelo relato de experiência, analisando de forma específica o Diagnóstico Rápido Participativo (DRP) e o Curso de Atualização em Educação de Jovens e Adultos (EJA) e Diversidade(s). Os resultados desta reflexão apontam que o foco EJA e diversidades, definido como eixo central das ações do CIVEJA, traduziu o compromisso da UNILAB com a integração e a interculturalidade e que as experiências desenvolvidas durante o citado projeto contribuíram para a discussão dos aspectos que caracterizam a EJA nos municípios abrangidos e se traduziram em um amplo processo educativo na perspectiva da extensão universitária referenciado na educação popular.

PALAVRAS-CHAVE: EJA; formação continuada; diversidades.

\section{TRAINING IN EJA AND DIVERSITY(IES): POPULAR EDUCATION EXPERIENCE FROM CIVEJA / UNILAB}

ABSTRACT: This study aims to reflect on the limits and possibilities found in development of Experiences of Intercultural Circuit in Youth and Adult Education (CIVEJA) - project linked to the Reference Center for Education Youth and Adult and South-South Cooperation (ECOSS) of the University of International Integration Lusophone African-Brazilian (UNILAB). Concerning to the method this text is an experience report, analyzing specifically the Rapid Participatory Diagnosis (DRP) and Course in Youth and Adult Education (EJA) and Diversity (s). The results of these considerations suggest that the EJA focus and diversity, defined as the centerpiece of CIVEJA actions, reflected the commitment of UNILAB with integration and intercultural and experiences acquired during the said project contributed to the discussion of the aspects that characterize the EJA in the covered municipalities and translated into a broad educational process from the perspective of university extension referenced in popular education.

KEYWORDS: Adult Education; continuing training; diversities. 
Elisangela André da Silva Costa; Jacqueline Cunha da Serra Freire; Ana Paula Sthel Caiado; Sinara Mota Neves de Almeida

\section{Introdução}

O direito à educação e a luta pela afirmação da Educação de Jovens e Adultos (EJA) no contexto brasileiro, principalmente nas décadas recentes, a partir da Constituição Federal de 1988 (BRASIL, 1988) e da Lei de Diretrizes e Bases da Educação Nacional (LDBEN) - Lei nº 9.394/1996 (BRASIL, 1996), tem promovido diferenciadas frentes de ação que englobam desde a formulação de diretrizes para a EJA, até sua inclusão no Fundo de Manutenção e Desenvolvimento da Educação Básica (BRASIL, 2007), simbolizando um conjunto de condições necessárias ao seu fortalecimento.

A formação continuada de professores destaca-se entre tais ações, sendo concebida como espaço de construção de conhecimentos sobre o ensinar e o aprender, de reflexão e de fortalecimento da profissionalidade docente (SACRISTÁN, 1995, p. 64), que conjuga elementos de natureza técnica, ética, política e estética (RIOS, 2008).

Os professores têm atuado como agentes de materialização das políticas educacionais, sendo, inclusive, algumas vezes responsabilizados por seu sucesso ou seu fracasso. Compreendemos que mais do que uma necessidade, a formação contínua se constitui como um direito (LIMA, 2001). Todavia, não são raras as experiências que se traduzem como pacotes de formação, esvaziados de uma perspectiva crítica, que possibilitem aos educadores problematizar, compreender e transformar suas práticas (IMBERNÓN, 2009).

As Instituições de Ensino Superior (IES) têm sido reconhecidas como importantes interlocutoras deste processo de formação e vêm ganhando relevância na construção da EJA enquanto política pública. Suas contribuições se dão tanto nos processos de formação inicial, a partir da incorporação da EJA nos currículos do ensino de graduação, quanto na formação contínua, por meio da pós-graduação e da extensão, ambas aliadas ao desenvolvimento de pesquisas na área. A parceria das IES com os sistemas e redes de ensino nas diferentes esferas - federal, estadual e municipal - tem cumprido um papel fundamental na formação de professores e no fortalecimento das políticas de EJA no Brasil.

O objetivo do presente trabalho é refletir sobre os limites e possibilidades encontrados no desenvolvimento do Circuito Intercultural de Vivências em Educação de Jovens e Adultos (CIVEJA), projeto vinculado ao Centro de Referência em Educação de Jovens e Adultos e Cooperação Sul-Sul (ECOSS), da Universidade da Integração Internacional da Lusofonia Afro-Brasileira (UNILAB), no período de 2013 a 2015.

Olh@res, Guarulhos, v. 4, n. 1, p. 335-350, maio 2016. 
A UNILAB é uma universidade pública federal que tem sua identidade pautada na integração internacional, especialmente com os Países Africanos de Língua Oficial Portuguesa (PALOP) - Angola, Cabo Verde, Guiné Bissau, Moçambique, São Tomé e Príncipe - e, ainda, Timor Leste (Ásia). Tendo sua missão institucional aliada ao desenvolvimento regional, a UNILAB se configura tanto como instrumento de fortalecimento da cooperação Sul-Sul, como de expansão e interiorização do ensino superior no Brasil.

Metodologicamente, a experiência do CIVEJA é abordada dentro deste relato a partir da análise do Diagnóstico Rápido Participativo (DRP) e do Curso de Atualização em Educação de Jovens e Adultos e Diversidade (s), tendo a reflexividade como princípio de articulação entre os elementos epistemológico, político e pedagógico presentes na proposta.

\section{CIVEJA: breve contextualização de experiência de educação popular}

O CIVEJA é uma iniciativa vinculada a ECOSS, que emergiu no contexto da implementação dos Centros de Referência em EJA, apoiados pelo Governo Federal através do DPEJA/SECADI/MEC, em articulação com universidades públicas, com vistas ao resgate da memória, levantamento e organização de acervos de EJA, fundamentado no ensino, pesquisa e extensão, bem como a constituição de uma rede com base comum, mantendo as especificidades de cada região.

A UNILAB inscreveu-se nesse contexto de fomento dos Centros de Referência em EJA na perspectiva de dialogar com as experiências brasileiras e implementar um Programa vocacionado para a cooperação internacional solidária com os PALOP, organizados em torno da Rede de Cooperação Sul-Sul entre os Países de Língua Oficial Portuguesa sobre Educação de Jovens e Adultos.

Compreendemos que a Educação de Jovens e Adultos é um componente essencial do direito à educação, cujo grande desafio posto, como foi apontado na VI Conferência Internacional da Educação de Adultos (CONFINTEA), realizada no Brasil em 2009, é o de “[...] passar da retórica à ação, envidando esforços para que as recomendações apresentadas no Marco de Ação de Belém sejam implementadas nas políticas públicas de Educação de Jovens e Adultos” (UNESCO, 2010, p. 3). 
A busca de uma EJA mais inclusiva e equitativa, referenciada na aprendizagem ao longo da vida, desafia o Estado-Nação em todo o mundo. Ao propormos a implementação e dinamização do CIVEJA, concebido como instrumento de diálogo, de reconhecimento da EJA no Brasil, a partir dos municípios situados na Região do Maciço de Baturité - Ceará, objetivamos promover ações socioculturais e educacionais com foco na EJA e diversidades, ancoradas no princípio da indissociabilidade ensino-pesquisaextensão.

As ações desenvolvidas foram dinamizadas de forma articulada, contemplando as múltiplas dimensões do CIVEJA: formação; comunicação e, ainda, mobilização social. Apostamos, com isto, na possibilidade de promover a inserção social da UNILAB no Maciço do Baturité e ampliar propositivamente os diálogos sobre EJA, na perspectiva da cooperação Sul-Sul.

A dimensão da comunicação contemplou a produção de Exposições virtual e itinerante de registros fotográficos, produção de vídeo-documentários, tendo como convergência a EJA no Maciço do Baturité e nos Países Africanos de Língua Oficial Portuguesa. O envolvimento da comunidade educacional e sociedade civil, com destaque à parceria com o Fórum de Educação de Jovens e Adultos do Ceará, foi o foco da dimensão da mobilização social.

O Diagnóstico Rápido Participativo (DRP) foi idealizado como uma contribuição para melhor conhecer a realidade educacional no Maciço de Baturité, especialmente da EJA, bem como subsidiar o desenho da formação continuada, vindo ao encontro de expectativas dos sujeitos educativos da EJA.

O Curso de Atualização em Educação de Jovens e Adultos (EJA) e Diversidade(s) ${ }^{1}$, vinculado ao componente da formação continuada do CIVEJA e expressão dos dados revelados pelo DRP, consistiu na oferta de atividades educativas/formativas com foco no fortalecimento da Lei 10.639/2003 (BRASIL, 2003) e de questões temáticas relacionadas à discussão sobre gênero, diversidade étnico-racial, cultura e religião, enfoque geracional, entre outros. Esta ação aliou-se à realização de

\footnotetext{
${ }^{1}$ No título do Curso o termo Diversidade(s) constitui-se um neologismo, cujo respaldo teórico inspira-se na origem etimológica da palavra, originada no latim diversitas, que guarda em seu significado as ideias de "diferença, à variedade, à abundância de coisas distintas ou à divergência" (HOUAISS, 1990). Esta expressão tem sido utilizada pelo Grupo de Pesquisa e Extensão Educação e Cooperação Sul-Sul, vinculado à UNILAB e registrado junto ao CNPq desde 2014. Para fins do presente artigo, no decorrer do texto o termo constará no singular referenciado no conceito abordado e será preservado o neologismo quando for referente ao nome do Curso.
} 
Círculos de Cultura que se propuseram a fortalecer e ampliar as discussões vivenciadas nos momentos de formação.

A diversidade é assumida como pilar estruturante do Curso, considerando as contribuições teóricas de Sacristán (2002), que situa historicamente o debate sobre heterogeneidade cultural como um fenômeno do final do século XX. Conceitualmente, o autor concebe que diversidade significa uma ruptura com a homogeneização que o universalismo cultural inspirou. $\mathrm{O}$ enfoque de ruptura paradigmática que $\mathrm{o}$ autor contextualiza e fundamenta referenciou o presente texto.

Organismos internacionais como a Organização das Nações Unidas para a Educação, a Ciência e a Cultura (UNESCO) têm incorporado a diversidade em sua agenda e formulação programática ${ }^{2}$, inclusive enfocando-a como direito, vetor de desenvolvimento e mais recentemente como base do diálogo entre os povos.

O CIVEJA pode ser entendido como uma iniciativa no campo da diversidade e das políticas públicas de educação, no sentido do que Rodrigues e Abramowicz (2011) abordam, em sua análise das condições teóricas, práticas e políticas que possibilitaram a ascensão do conceito de "diversidade", no contexto das políticas educacionais entre os anos de 2003 a $2006^{3}$.

Obras de Paulo Freire $(1983,1987)$ foram indispensáveis para subsidiar o trabalho do CIVEJA, na perspectiva de melhor compreender elementos relacionados à experiência de EJA no Maciço do Baturité e referenciar as ações de extensão universitária popular.

A educação popular é um campo imbricado na história da educação, especialmente, na América Latina e no Brasil. Comprometida com as camadas populares da sociedade, a educação popular é historicamente estruturante na inclusão social em nosso país.

O legado de Paulo Freire é incontestavelmente um dos principais aportes teóricos e metodológicos no campo da educação popular, de (re)valorização de saberes e práticas sociais produzidas nas experiências de vida e comunidades populares, muitas vezes marginalizadas pela sociedade e seus construtos hegemônicos.

\footnotetext{
${ }^{2}$ Inscrita na sua Constituição de 1945, a UNESCO reconhece a importância da diversidade como valor intrínseco das culturas.

${ }^{3}$ Período que compreende o primeiro mandato do ex-Presidente Luis Inácio Lula da Silva, no Brasil.
} 
Brandão (2002) aborda quatro enfoques principais para reflexão sobre a educação popular e seu escopo conceitual e de práticas. Alinhamo-nos com a abordagem do autor de que educação popular é:

[...] algo realizado como um acontecimento situado e datado, caracterizado por um esforço de ampliação do sentido do trabalho pedagógico a novas dimensões culturais, e a um vínculo entre a ação cultural e a prática política. A educação popular foi e prossegue sendo uma sequência de ideias e de propostas de um estilo de educação em que tais vínculos são reestabelecidos em diferentes momentos da história, tendo como foco de sua vocação um compromisso de ida - e - volta nas relações pedagógicas de teor político realizadas através de um trabalho cultural estendido a sujeitos das classes populares compreendidos como não beneficiários tardios de um "serviço", mas como protagonistas emergentes de um "processo" (BRANDÃO, 2002, p.141-142).

A educação popular é essencialmente uma pedagogia libertadora, em que a práxis educativa é perpassada pela ação dialógica, a teoria e a prática são imbricadas, a educação bancária e tradicional é refutada. Freire (1987, p.109-110) afirma que:

\footnotetext{
Não há conscientização se, de sua prática não resulta a ação consciente dos oprimidos, como classe explorada, na luta por sua libertação. Por outro lado ninguém conscientiza ninguém. $\mathrm{O}$ educador e o povo se conscientizam através do movimento dialético entre a reflexão crítica sobre a ação anterior e a subsequente no processo de luta.
}

Desse modo, o conjunto de ações realizadas se constitui como forma de conscientização e de empoderamento dos sujeitos envolvidos, numa perspectiva de emancipação comprometida com a humanização.

\section{DRP e a produção de conhecimento no CIVEJA: apontamentos sobre a EJA no Maciço de Baturité}

O DRP sobre EJA nos municípios abrangidos pelo CIVEJA - Acarape, Aracoiaba, Baturité e Redenção - destacou-se como uma das ações, no processo de implementação do Projeto. No entanto, na perspectiva de dinamizar a formação continuada de professores, a abrangência foi ampliada para outros municípios do Maciço do Baturité Barreira, Palmácia, Ocara, Capistrano, Aratuba, Guaramiranga, Pacoti, Itapiúna, Mulungu e Guaiúba - região no estado do Ceará onde a UNILAB está implantada e atua prioritariamente.

As contribuições trazidas pelo DRP através do mapeamento da realidade local fizeram com que as atividades das diferentes dimensões do CIVEJA (formação, comunicação e mobilização social) descortinassem os desafios, necessidades e 
potencialidades da EJA nos municípios, atuando de forma histórica e socialmente situada. Desse modo, tais contributos podem ser apontados como produtos evidentes da articulação entre ensino-pesquisa-extensão.

A análise de Verdejo (2006, p. 14) aponta que diferentemente de métodos convencionais de pesquisa, o DRP recorre à diversificação de fontes para uma coleta compreensível da informação, é uma metodologia referenciada em três pilares básicos: a participação, o comportamento e as técnicas de levantamento de campo. Segundo o autor, o DRP “[...] permite colher dados de maneira ágil e oportuna. Apesar de sua rapidez, a coleta de dados não é incompleta nem superficial". Conforme analisado por Gomes, Souza e Carvalho (2001, p. 66):

[...] esse método foi direcionado para adquirir rápida e eficientemente novas informações e hipóteses sobre a vida e os recursos no meio rural (Charuthers \& Chambers, 1981, citados por Schönhuth \& Kievelitz, 1993). Uma equipe multidisciplinar sistematiza uma atividade semiestruturada de coleta de dados exercida diretamente no local, ficando num campo intermediário entre estudos de áreas especificas e levantamentos estatísticos-formais amplos [...].

A compreensão metodológica sobre experiências de DRP e seus fundamentos foi essencial para subsidiar o levantamento de dados sobre EJA no Maciço do Baturité, a elaboração de seus instrumentos e o desenvolvimento do mesmo, com o propósito de mapear elementos da realidade na região; identificar demandas de formação de professores/as e gestores/as a fim de subsidiar ações institucionais da UNILAB.

Com a dinâmica que o DRP, foi realizado um levantamento que possibilitou o mapeamento de dados primários de mais de $50 \%$ dos municípios sobre formação de professores de EJA. No que se refere aos dados secundários, $100 \%$ dos municípios na área de atuação do Projeto foram caracterizados. Os resultados possibilitaram conhecer mais sobre a EJA nos municípios, bem como contribuir para ações de extensão que fortaleceram o diálogo intercultural em nível loco-regional e com experiências internacionais de EJA.

Os dados do DRP revelaram, ainda, que a taxa de analfabetismo nos municípios pesquisados no Maciço do Baturité são substantivamente mais elevadas em relação à média nacional. Os municípios estão situados na faixa de Índice Desenvolvimento Humano Médio (IDHM) entre 0,6 e 0,699 e apresenta, no intervalo entre 2000 e 2010, a educação como a dimensão que mais cresceu. Em que pese apresentar dados mais elevados em relação à média nacional, a taxa de analfabetismo da população de 18 anos ou mais diminuiu em 20,07\% na cidade de Acarape; 24,87\% em Aracoiaba; 18,65\% em Baturité e 21,51\% em Redenção, nas últimas duas décadas. 
Elisangela André da Silva Costa; Jacqueline Cunha da Serra Freire; Ana Paula Sthel Caiado; Sinara Mota Neves de Almeida

No que se refere ao diagnóstico da formação de professores, que envolveu gestores da EJA, os dados revelaram que o nível de formação mais elevado está na rede estadual, em que todos são graduados. Na rede municipal, parcela significativa tem nível superior incompleto e/ou ensino médio. Os dados revelaram que não há uma política de formação continuada de professores nessa modalidade de ensino, o que amplia a responsabilidade da UNILAB e seu compromisso com a inserção social no Maciço do Baturité.

A demanda por formação continuada pelos participantes do DRP foi centrada em questões do letramento, numeracia, temas transversais, direitos humanos, história e cultura afro-brasileira e profissionalização. A relação entre educação e o mundo do trabalho se constituiu como objeto de acentuada preocupação, na perspectiva da inclusão social.

A Secretaria Estadual de Educação (SEDUC) vem dinamizando a EJA no Ceará, como modalidade constitutiva do sistema estadual de ensino. Destaca-se na política estadual de EJA a presença dos Centros de Educação de Jovens e Adultos (CEJA) que se constituem em unidades de ensino focadas na EJA. A estrutura institucional dos CEJA é flexível, aceita matrícula em qualquer época do ano letivo e trabalha com a modalidade semipresencial. O processo pedagógico proporciona uma interação direta, inclusive com atendimento individual, sob forma de plantão entre educador e educando, em que a valorização do intercâmbio de experiências, saberes, cooperação e diálogo são valores fundantes da relação pedagógica.

A leitura crítica da realidade proporcionada pelo DRP revelou que os sentidos da EJA nos múltiplos olhares dos educadores do Maciço são perpassados por experiências educacionais marcadas pela EJA como elemento de inclusão social e exercício da cidadania; esforços na inovação pedagógica; valorização dos contextos locais articulados com realidades mais amplas.

Os municípios revelaram esforços concentrados em fomentar ações que fortaleçam a EJA, dinamizando projetos educativos sintonizados com a realidade local e os desafios contemporâneos. A demanda por profissionalização traduz a perspectiva de implementar políticas inclusivas, aliadas a processos de valorização da diversidade e das diferenças. 


\section{A materialização do CIVEJA: um olhar sobre a formação}

Vinculado ao componente da formação continuada do CIVEJA, o Curso de Atualização em Educação de Jovens e Adultos (EJA) e Diversidade(s) se consistiu na oferta de atividades educativas/formativas envolvendo questões temáticas relacionadas à discussão sobre gênero, diversidade étnico-racial, cultura e religião, enfoque geracional, entre outros. Concebido e implementado a partir dos elementos sinalizados no DRP, o Curso primou pelos princípios da interdisciplinaridade e interculturalidade, alinhados com as discussões temáticas elencadas, na perspectiva do fortalecimento da Lei 10.639/2003 (BRASIL, 2003) e da Lei 11.645/2008 (BRASIL, 2008).

A Lei 10.639, de 09 de janeiro de 2003 (BRASIL, 2003), que altera a LDBEN, estabelece as Diretrizes e Bases da Educação Nacional para incluir no currículo oficial da Rede de Ensino a obrigatoriedade da temática "História e Cultura Afro-Brasileira", completou 10 anos em 2013 e os desafios são complexos na sua implementação.

Parte constitutiva de um importante marco legal de políticas afirmativas no Brasil, a Lei 10.639/2003 (BRASIL, 2003) estabelece a inclusão do estudo da História da África e dos Africanos, a luta dos negros no Brasil, a cultura negra brasileira e o negro na formação da sociedade nacional, resgatando a contribuição do povo negro nas áreas social, econômica e política, pertinentes à História do Brasil.

A definição das temáticas abordadas na formação levou em consideração, além dos fatores pertinentes à EJA, a identidade institucional da UNILAB. Criada através da Lei 12.289/2010 (BRASIL, 2010), esta universidade é vocacionada para a cooperação internacional e compromissada com a interculturalidade, a cidadania e a democracia nas sociedades. Assim, o eixo articulador da formação intitulado "Educação de Jovens e Adultos e diversidade(s)" materializa o compromisso institucional de "promoção da interculturalidade; o respeito à ética e à diversidade, defesa dos direitos humanos" entre outros objetivos postos no art. $5^{\circ}$ do Estatuto da UNILAB, além colaborar com a implementação da Lei 10.639/2003 (BRASIL, 2003).

A organização curricular do curso norteou o diálogo entre os eixos temáticos constituintes da proposta de formação, quais sejam: "Marcos Estratégicos da EJA; Educação ao Longo da Vida; Currículo, Cultura e Diversidades; EJA, Conhecimentos e Múltiplas Linguagens; EJA: cidadania, saberes e práticas educativas”.

O curso foi integralizado em 120 horas, mediante a participação dos professores em momentos presenciais e em atividades à distância, mediadas pelo Ambiente Virtual 
Elisangela André da Silva Costa; Jacqueline Cunha da Serra Freire; Ana Paula Sthel Caiado; Sinara Mota Neves de Almeida

de Aprendizagem (AVA), sendo 50\% da carga horária para cada modalidade e acompanhado por duas professoras, seis tutores e coordenação pedagógica. Foram contabilizados 212 ingressantes e certificados 170 participantes do conjunto dos municípios que aderiram ao CIVEJA.

O uso das Novas Tecnologias da Informação e Comunicação (NTIC), neste contexto, teve duas finalidades: a superação das barreiras geográficas que limitavam as possibilidades de encontros presenciais mais sistemáticos; e o empoderamento dos educadores através dos processos de mediação realizados no AVA, que os colocavam em permanente contato com fontes diversas de informação e com o desafio de refletir sobre a própria prática, socializando seus registros de forma escrita. Tal processo demandou tanto a construção de conhecimentos sobre as NTIC, quanto a compreensão das novas abordagens pedagógicas, como caminhos que permitissem superar o isolamento do professor no contexto da escola, colocando-o "em permanente situação de diálogo e cooperação" (KENSKI, 2013, p. 66).

As atividades foram realizadas em dois Polos, sendo um no município de Baturité e o outro em Redenção. Cada Polo aglutinou diferentes municípios, sendo eles no Polo Baturité: Aracoiaba, Aratuba, Baturité, Capistrano, Guaramiranga, Itapiúna, Mulungu, Pacoti; e Polo Redenção: Acarape, Barreira, Ocara, Palmácia, Redenção e Guaiúba.

O acompanhamento pedagógico das atividades à distância era realizado por professoras e tutores que, além da graduação, apresentavam pós-graduação lato ou strito sensu e, ainda, atuação no campo da EJA. Os formadores que conduziam os momentos presenciais eram todos vinculados a instituições parceiras da UNILAB, convidados para serem mediadores de discussões e aprofundamentos teóricos e metodológicos da EJA, tendo formação em nível de doutorado, em sua maioria, ou mestrado. Residualmente teve a atuação de graduado em nível da formação continuada.

Através da articulação dos eixos do CIVEJA, ampliamos ainda mais o olhar sobre a EJA, situando-a como um direito historicamente construído a partir da participação de muitos. Os Círculos de Cultura realizados no curso inspiraram-se na obra de Paulo Freire $(1983,1987)$ e foram concebidos como encontros entre sujeitos educativos, engajados em atividades socioeducacionais e culturais. Seguindo esta mesma inspiração, as palestras eram sempre seguidas de Círculos de Diálogos Temáticos, visando o aprofundamento teórico-metodológico, interações e troca de experiências entre os municípios, mediada pela temática das palestras e leituras sugeridas. 
No sentido de dinamizar ainda mais o curso, foram propostas, também, Cirandas da Diversidade, com vivências interculturais e de reflexão sobre as temáticas do CIVEJA, e momentos lúdicos, com atividades de relaxamento, animação, dentre outros. Por fim, os professores participantes foram convidados a atuar como pesquisadores, realizando atividades exploratórias com vistas à coleta de materiais para a constituição de produtos distintos referentes à EJA no Maciço de Baturité: a exposição itinerante e virtual de registros fotográficos e vídeo-documentários.

A Exposição contemplou vídeos e banners que foram produzidos por professores de EJA dos municípios do Maciço de Baturité, na perspectiva do compartilhamento de suas experiências pedagógicas, da qual participaram professores(as), educadores(as) e gestores(as) da EJA e da Educação Básica de um modo geral. Todo o material, contendo registros fotográficos e escritos sobre as experiências em EJA, foi socializado na ocasião de certificação dos professores participantes do Curso de Atualização de Educação de Jovens e Adultos e Diversidade(s), na UNILAB, no Campus da Liberdade em Redenção/CE.

Assim, a Exposição revelou a grande diversidade da EJA, com experiências educacionais dinamizadas no sistema prisional, na educação indígena, de incentivo da leitura, conscientização de hábitos alimentares saudáveis, valorização do folclore, entre outras.

A organização dos materiais foi dividida em três eixos: História e memória da EJA nos municípios e nos CEJA; Experiências recentes e atuais de EJA nos municípios e nos CEJA e por fim Experiências de EJA em contextos interculturais e diversidade(s). Os materiais coletados pelos professores foram recolhidos pela coordenação do CIVEJA, junto com documentos de autorização de uso de sons e imagens, para serem tratados e posteriormente postados no portal ECOSS, junto a outros registros já realizados pela equipe nas missões enviadas a países africanos.

O memorial fotográfico, produzido a partir das atividades do curso, nos permitiu compreender o processo de integração e nos revelou resultados positivos do trabalho. Através de fotografias e depoimentos escritos pelos professores pudemos constatar, compreender e compartilhar as experiências de EJA em seus locais de trabalho e comunidades.

Como foi possível visualizar, o CIVEJA, desde seu planejamento, constitui-se como uma experiência inovadora que traduz o compromisso com a EJA, mediante a formação dos professores, a socialização de informações sobre as ações voltadas a jovens 
e adultos pouco ou não escolarizados e a mobilização social em torno do direito à educação.

\section{Análise da experiência: reflexividade e colaboração como elementos formativos}

De acordo com o projeto que lhe deu origem, o CIVEJA se constitui numa proposta de ação de extensão universitária ancorada no tripé da indissociabilidade ensinopesquisa-extensão, concebido como um intercâmbio de múltiplos olhares. "A sonorização da palavra remete para nos vermos, nos olharmos. Nesse caso, são múltiplos olhares sobre as vivências em EJA no Maciço do Baturité e nos países parceiros do ECOSS” (UNILAB, 2014, p. 3).

O convite para cada professor "se ver e se olhar" dentro do processo de formação, na condição de sujeito, nos permite verificar a relação entre a perspectiva formativa proposta pelo CIVEJA e a conceituação de formação contínua apresentada por Lima (2001, p. 115) como “[...] o processo de articulação entre trabalho docente, conhecimento e desenvolvimento profissional do professor, como possibilidade de uma postura reflexiva dinamizada pela práxis". A mediação nos processos de reflexão sobre a prática e construção de conhecimentos envolveu a interação entre os sujeitos de maneiras distintas, metodologicamente pensadas para contribuir para a construção de diferentes habilidades e atitudes (UNILAB, 2014).

Partindo desta premissa, a prática dos formadores fundamentou-se numa perspectiva reflexiva e não prescritiva de formação, corroborando com a ideia de que estes profissionais devem ajudar os professores a "analisar os obstáculos (individuais e coletivos) que o professorado encontra para ter acesso a um projeto formativo que os ajude a melhorar" (IMBERNÓN, 2009, p. 105). Neste sentido, a atuação conjunta de todos os formadores colaborou para a ampliação da visão de mundo dos educadores sobre a EJA e sobre si mesmos, na condição de professores e de sujeitos históricos que se constroem a partir das diferentes relações que estabelecem com o mundo.

Relacionamos a este movimento de reflexão, o contexto das práticas, compreendidas como ações encharcadas por visões e projetos de mundo quase sempre distintos, ou mesmo antagônicos, que precisam ser percebidas de modo crítico pelos sujeitos, para que tenham clareza da não neutralidade de seu trabalho. 
A reflexão sobre a prática, dentro da visão apresentada, pode ser considerada práxis transformadora (VAZQUEZ, 1977), associada à figura do professor, como um intelectual crítico, historicamente situado, que reflete sobre sua prática e sobre as determinantes que a perpassam, visando à construção de novos modos de pensá-la e de manifestá-la.

A reflexão pode, ainda, compreender ideias como movimento introspectivo a partir do qual o pensamento volta-se sobre si mesmo, possibilitando o exame das próprias ações e identificação dos princípios que as sustentam; o imergir consciente do sujeito historicamente situado no mundo da sua própria experiência, no qual se encontram os valores e os significados (GÓMEZ; SACRISTÁN, 1998). Tais compreensões apontam para um movimento que permite ao sujeito o encontro consigo mesmo e com as trajetórias de construção de suas visões de mundo, educação e profissão, trazendo para o cenário da reflexão diferentes dimensões do processo de construção identitária: histórica, social, relacional, afetiva.

Assim, a reflexão nos processos formativos permite compreender a identidade profissional docente como processo e não como um produto, como lugar de conflitos, buscas e incertezas, como movimento e, por fim, como atitude de construção de maneiras de ser e estar na profissão (NÓVOA, 1992).

Ao pensar criticamente a prática e ler criticamente a realidade, o educador é impulsionado a agir, a transformar a realidade. Nesse sentido, a perspectiva colaborativa vem ganhando relevância tanto dentro dos espaços de formação, quanto de trabalho do professor.

A integração, o fortalecimento das identidades, a construção do conhecimento sobre a docência na EJA e seus sujeitos, viabilizados através de diferentes momentos de problematização da prática docente, possibilitou a todos os participantes (professores cursistas, bolsistas da universidade, professores formadores e equipe coordenadora) oportunidades de desenvolvimento pessoal e profissional. Dentre tais oportunidades destacam-se aquelas pertinentes às dimensões da comunicação e da mobilização social, que geralmente não são abordadas em processos formativos, mas que se revestem de grande potencial reflexivo e colaborativo. 


\section{Considerações finais}

O ponto de partida da formulação do CIVEJA é a compreensão da EJA como um direito, conquistado a partir do esforço e mobilização de muitos. Tal direito, no entanto, precisa ser reafirmado, cotidianamente, sob pena de se reduzir a uma compreensão restrita de formação como instrução. Nesse sentido, a formação de professores se constitui tanto como uma necessidade, quanto como um direito do professor, uma vez que a atuação deste profissional interfere de forma direta, embora não exclusiva, no acesso, na permanência e no sucesso dos alunos de EJA.

As ações do CIVEJA, conforme foi possível visualizar neste relato, integraram as dimensões da formação, da comunicação e da mobilização social. Apesar de apresentarem características distintas, tais dimensões representam um todo que, integrado, possibilitou aos professores participantes experiências relacionadas à concepção da educação como um ato político, compromissado com o desenvolvimento e com a emancipação humana.

O CIVEJA revelou-se uma experiência educacional inédita na região, contribuindo significativamente na formação continuada dos sujeitos educativos envolvidos. A pertinência de seus objetivos, metodologia proposta e coerência, na oferta do curso evidenciou-se na análise documental.

A formação continuada com foco na EJA e diversidade(s) possibilitou a todos os participantes oportunidades de (re)conhecimento da EJA no Maciço de Baturité e também de integração entre os educadores de diferentes municípios.

O memorial fotográfico, produzido a partir das atividades do curso de atualização, permitiu compreender o processo de integração e nos revelou resultados positivos do trabalho. Através de fotografias e depoimentos escritos pelos professores pôde-se constatar, compreender e compartilhar as experiências de EJA em seus locais de trabalho e comunidades.

A Exposição revelou a grande diversidade da EJA no Maciço, retratando experiências diferenciadas com sujeitos de comunidades específicas e temáticas que emergem de suas necessidades cotidianas, como trabalho, alimentação, educação, cultura, entre outros.

O CIVEJA contribuiu significativamente para a inserção social da UNILAB no Maciço do Baturité; bem como para a articulação da universidade com a educação básica, especialmente na modalidade EJA, historicamente excluída nos cursos de licenciatura. 
Destaca-se, ainda, o alcance exitoso dos propósitos do curso, contribuindo com uma educação pública de qualidade e pertinência social.

Assim, é legítimo afirmar que o CIVEJA contribuiu para a melhoria da qualidade da EJA no Maciço de Baturité. Que experiências desta natureza possam aproximar cada vez mais a universidade das escolas e dos movimentos sociais, no sentido de cumprir com o seu papel social de promover o desenvolvimento dos locais onde se estabelece, através do desenvolvimento dos indivíduos.

\section{REFERÊNCIAS BIBLIOGRÁFICAS}

BRANDÃO, C. R. A educação popular na escola cidadã. São Paulo: Editora Vozes, 2002.

BRASIL. Lei 12.289, de 20 de julho de 2010. Dispõe sobre a criação da Universidade da Integração Internacional da Lusofonia Afro-Brasileira - UNILAB e dá outras providências. Brasília, 2010. Diário Oficial da União, Brasília, 21 jul. 2010. Seção 1, Página 4.

Lei $\mathrm{n}^{\circ} 11.645$, de 10 de março de 2008. Altera a Lei no 9.394, de 20 de dezembro de 1996, modificada pela Lei no 10.639, de 9 de janeiro de 2003, que estabelece as diretrizes e bases da educação nacional, para incluir no currículo oficial da rede de ensino a obrigatoriedade da temática "História e Cultura Afro-Brasileira e Indígena”. Brasília, 2008. Diário Oficial da União, Brasília, 11 mar. 2008. Seção 1, Página 1.

Lei no 11.494, de 20 junho de 2007. Regulamenta o Fundo de Manutenção e Desenvolvimento da Educação Básica e de Valorização dos Profissionais da Educação FUNDEB. Brasília, 2007. Diário Oficial da União, Brasília, 21 jun. 2007. Seção 1, Página 7.

Lei $\mathrm{n}^{\circ} 10.639$, de 09 de janeiro de 2003. Altera a Lei $\mathrm{n}^{\circ}$ 9394, de 20 de dezembro de 1996, que estabelece as diretrizes e base da educação nacional, para incluir no currículo oficial da Rede de ensino a obrigatoriedade da temática "História e Cultura Afro-brasileira" e dá outras providências. Brasília, 2003. Diário Oficial da União, Brasília, 10 jan. 2003. Seção 1, p.1.

. Ministério da Educação. Lei 9394/96, de 20 de dezembro de 1996. Estabelece as Diretrizes e Bases da Educação Nacional. Diário Oficial da União, Brasília, 23 dez. 1996. Seção 1, Página 27833.

Constituição Federal de 1988, de 05 de outubro de 1988. Brasília, 1988. Diário Oficial da União, Brasília, 05 out. 1996. Seção 1, Página 1.

FREIRE, P. Educação como prática da liberdade. 14. ed. Rio de Janeiro: Paz e Terra,1983. 
Elisangela André da Silva Costa; Jacqueline Cunha da Serra Freire; Ana Paula Sthel Caiado; Sinara Mota Neves de Almeida

Pedagogia do Oprimido. 17. ed. Rio de Janeiro: Paz e Terra, 1987.

GOMES, M. A. O.; SOUZA, A. V. A.; CARVALHO, R. S. de. Diagnóstico Rápido Participativo (DRP) como mitigador de impactos socioeconômicos negativos em empreendimentos agropecuários. In: BROSE, M. Metodologia participativa: uma introdução a 29 instrumentos. Porto Alegre: Tomo Editorial, 2001. p. 63-78.

GÓMEZ, A. P.; SACRISTÁN, J. G. Comprender e transformar o ensino. 4. ed. Porto Alegre: Artmed, 1998.

HOUAISS, A. Dicionário Houaiss da Língua Portuguesa. Rio de Janeiro, Ed. Objetiva, 2001.

IMBERNÓN, F. Formação permanente do professorado: novas tendências. São Paulo: Cortez, 2009.

KENSKI, V.M. Educação e tecnologias: o novo ritmo da informação. 8.ed. São Paulo: Papirus, 2013.

LIMA, M. S. L. A formação contínua de professores nos caminhos e descaminhos do desenvolvimento profissional. 2001.165p. Tese (Doutorado em Educação) Universidade de São Paulo. São Paulo, 2001.

NÓVOA, A. Formação de professores e profissão docente. In: A. Nóvoa (org.). Os professores e sua formação. Lisboa: Nova Enciclopédia, 1992. p.15-34.

RIOS, T. A. Compreender e ensinar: por uma docência da melhor qualidade. 7. ed. São Paulo: Cortez, 2008.

RODRIGUES, T. C.; ABRAMOWICZ, A. Diversidade e as políticas públicas de educação. Revista Contrapontos. Vol. 11, n. 3, 2011. p. 244-254.

SACRISTÁN, J. G. A construção do discurso sobre a diversidade e suas práticas. In: ALCUDIA, R. (Org.). Atenção à diversidade. Porto Alegre: Artmed, 2002.

UNILAB. Projeto do Circuito Intercultural de Vivências em EJA. Redenção: UNILAB, 2014.

VAZQUEZ, A. S. Filosofia da Práxis. Rio de Janeiro: Paz e Terra, 1977.

VERDEJO, M. E. Diagnóstico Rural Participativo: guia prático DRP. Brasília: MDA/ Secretaria da Agricultura Familiar, 2006.

UNESCO. CONFINTEA VI: Marco de ação de Belém. Brasília: 2010.

Recebido em: 20/02/2016

Aprovado em: 28/04/2016 